\title{
Modelling the Investment Behaviour of British Life Offices 1963-77
}

\author{
by J. C. Dodds *
}

\section{Introduction}

Insurance has been an important method by which the problem of risk in the world of business and in the life of the individual person has been met. Life offices in this process provide two functions. In the first place they provide cover against the risk of death, and secondly they act as investment managers by providing a guarantee of future capital security and of long-term investment yield.

Unlike the U.S.A., the study of the investment of British life companies has been a relatively neglected research area, yet they channel over $30 \%$ of personal sector saving (as measured by premium income) each year and play a significant role in a large number of financial markets, particularly the market for company and Government fixed interest securities. The work that has been produced on the industry has mainly been of a descriptive nature, although in the past few years there have been a few small incursions into portfolio models. ${ }^{1}$ The present paper, ${ }^{2}$ which concentrates on an industry wide study rather than a cross-sectional analysis, represents a partial attempt to fill this apparent lacuna.

In Section 2 we analyse the asset portfolio distributions of life companies and examine some of the factors underlying the investment process. We introduce a stock adjustment mechanism which can take account of both stock and flow influences which we develop in Section 3. We present two overall models; one static and the other dynamic. A sequential investment process is proposed rather than a simultaneous allocation of funds across all asset classes. Section 4 is by way of a conclusion and perspective.

\section{The portfolio characteristics of life companies}

In table 2.1 we present an overview of two aspects of the portfolio of assets, namely annual holdings and net acquisitions. It indicates that life companies are very

* University of Sheffield.

1 For the descriptive studies we may cite R. L. Carter [1], G. Clayton [4], G. Clayton and W. T. Osborn [5], G. M. Dickinson [7] and P. J. Franklin and C. Woodhead [10]. For portfolio models see A. Munro [11], T. M. Ryan [12] and for a critique of Ryan see J.-C. Dodds [8]. For a rather recent but more limited study see R. L. Carter and J. E. V. Johnson [2].

2 For a more complete coverage see J. C. Dodds [9]. 


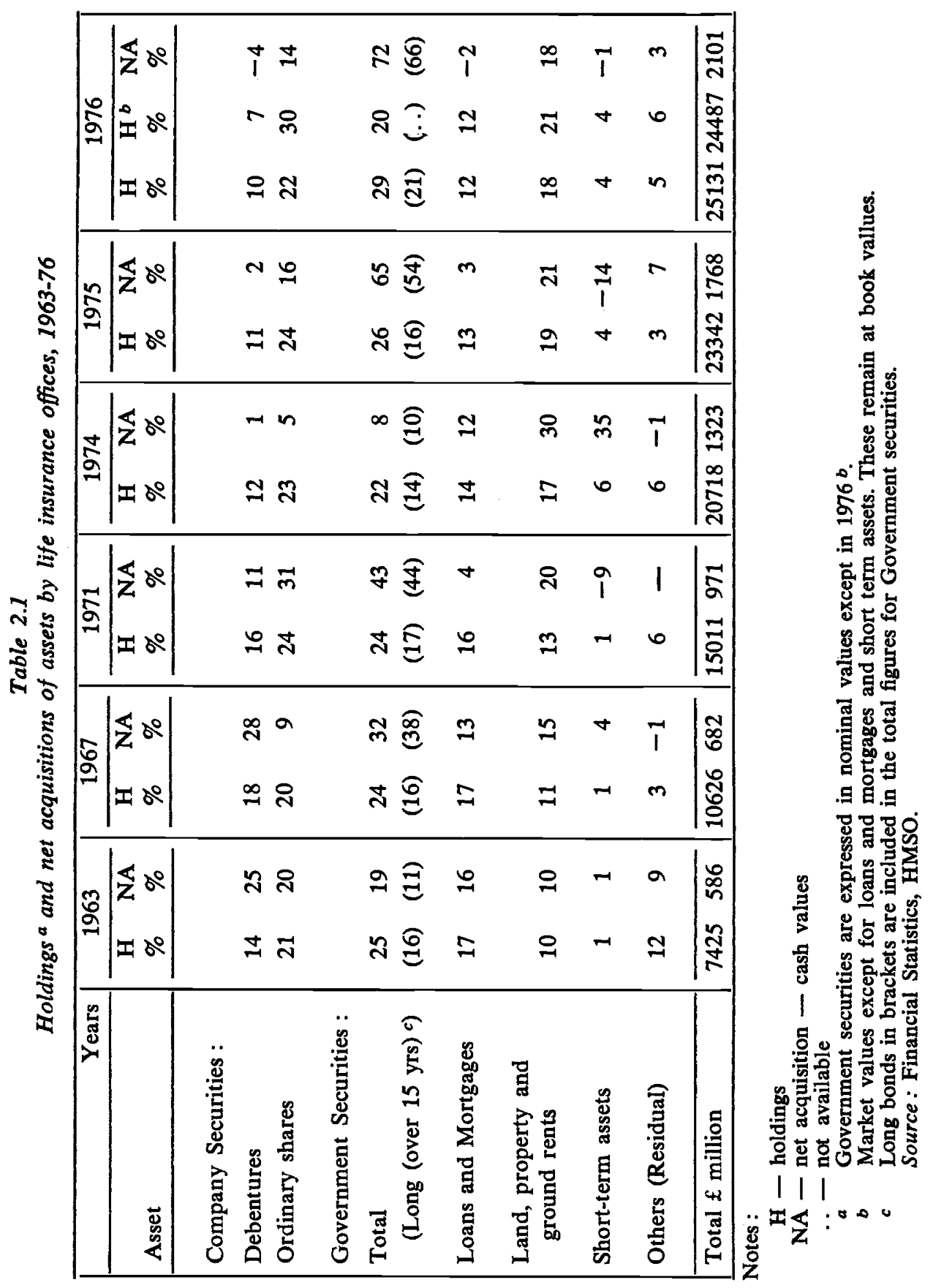


diversified in terms of type of financial claims held, but the table also illustrates the variability of net acquisitions. ${ }^{3}$ In consequence it would appear that the investment decision process is not solely one of directing net new funds, but also one of reviewing the holdings of the existing portfolio. What would be under review would be the choice between fixed interest securities (such as government securities, debentures and mortgages), equity assets (ordinary shares and property) and short-term assets. It is these strategic decisions that are examined in this paper, though of course we recognise that the allocation decision within these investment classes is also an important matter of concern. In effecting the strategic choice process the life company may be characterised as having a desired or optimum balance sheet. Of course, this equilibrium structure will not be directly observed, though we can argue that its exact formulation will be determined by the preference of the investment manager concerned (e.g., his attitude towards risk), the product mix of the liabilities (e.g., group pension business, annuities, term assurance, whole life endowment), and the nature of the assets themselves with respect to their yield and other attributes (e.g., for instance, income and capital riskiness both in nominal and real terms, investibility, and non-yield factors, such as the flow of new business which may come from the granting of house purchase loans).

To capture the assumption that life companies adjust towards an optimum balance sheet we can utilise a standard stock-adjustment mechanism as in equation (2.1) :

$$
A^{a}{ }_{t}=A_{t-1}^{a}+\alpha\left(A_{t}^{*}-A^{a}{ }_{t-1}\right) \quad 0<\alpha<1
$$

where $A^{a}$ represents the actual demand for asset $A$, and $A^{*}$ is the desired or optimum holding of that asset. Although those desired levels are not directly observable, it is generally argued that we can specify $A^{*}{ }_{t}$ as a function of yield and non-yield factors, as well as of the size of the existing holdings of the asset.

If we were to take $A^{a}{ }_{t-1}$ to the left hand side of equation (2.1), we would have an expression explaining the change in the holding of asset $A$, period by period. Equation (2.1) thus embodies a simple dynamic relationship in actual values, which are measurable, and the desired value, which is given by the desired demand/supply equation. This adjustment is often portrayed by means of a lagged dependent variable in the equation under consideration and this is the formulation we adopt in Section 3.

Life companies may be in a state of disequilibrium for a number of reasons. The degree of adjustment required might be so large that this cannot be effected in terms of immediate readjustment of holdings (without producing an adverse effect on the market) or use of new funds to buy stock. Indeed the right type of security is not always available so that life offices may be forced to use holdings of short-term assets until they can make more permanent allocations. This would particularly be the case if there were an unexpected increase in new funds and search costs which can cause inertia.

3 Net acquisitions data are in cash values and they are the data (on a quarterly basis) that are utilised for the econometric model in Section 3. They are the result of netting out purchases and sales of securities in a given period. They are not strictly first differences of stocks because they cannot take account of revaluations of the holdings of assets. 
Differing emphasis can still be given to stock and flow influences. Models which focus on flows are referred to as "flow of funds" models and the justification for utilising them is that given the volume of inflowing funds, a switch in the allocation of these funds can usually bring about any desired change in overall proportions, without the need to disturb the existing holdings themselves. If we analysed the extreme position of a flow model, it could be characterised as a fixed coefficient input-output model. Flow models can imply a more defensive attitude to investment and the performance of the portfolio as they do not require the disturbance of the inherited holdings of the portfolio, period by period. Stock models do, however, allow for the shuffling of the existing portfolio (within market constraints) as well as the allocation of new funds. These models are often referred to as "speculative". But to view the "flows" and "stock" models as alternatives is to dichotomise the investment process unnecessarily and an examination of Table 2.1 would appear to suggest both viewpoints at work in that as we have seen, the net acquisitions of some assets are very variable and can be negative, thus indicating a run-down of a stock position.

In both broad types of models, interest rates are an important factor in determining the investment decision and this brings us to the need to specify "expected returns". Indeed the actuarial literature puts forward maximization of expected yield as the unitary objective of life companies. We can define the "expected return" of an asset in terms of the holding until maturity (in the case of dated securities), then some assumption has to be made as to the holding period. A common viewpoint, no doubt influenced by balance sheet considerations, points to a one year assessment and this is to be found in the literature appertaining both to the U.K. and the U.S.A. With a known holding period then the expected yield is calculated by combining coupon or dividend payments due (if any) with an estimate of the expected capital gain. The expected yield can then be calculated as a return on the acquisition price of the asset. In the main however, as it is difficult to be precise on holding periods, expected yields are either calculated using mechanistic schemes based on past data of spot rates, or investment managers are assumed to have "static expectations" such that the yield holding in $t$ is assumed to hold in $t+1$. This latter viewpoint does find some support in relation to life companies in H. C. Cottrell [6] and H. G. Clark [3] as well general support in the applied economics literature. We use this line of reasoning in the models presented in Section 3.

\section{Model of investment behaviour, 1963-77}

The assets for which we present results are those listed in Table 2.1, namely debentures, loans and mortgages, government securities, ordinary securities, property and short-term assets. Whilst it could be argued that all assets compete simultaneously for the available funds, we instead suggest a sequential investment process. The basis for this segmentation rests in the main on what we feel fits the facts, though we appreciate that the precise ordering of the allocation may be open to question and indeed may change through time. Our argument is that the two assets that do receive prior consideration for the available funds are loans and mortgages and debentures. The case for the former rests on the passiveness that life offices have displayed in 
granting house purchase loans to increase the overall business of the office. Since house loans appear to be virtually demand determined, we would not expect them to be sensitive to yield. For debentures the case is rather different. The secondary market is very thin, unlike the markets in government securities and ordinary shares, so new acquisitions are usually acquired by subscribing to new issues and/or as a result of the underwriting of these issues. In consequence if new issues are available and the yield premium over similar government securities sufficient to compensate the relative lack of marketability (and default risk) the debenture can be a choice asset, particularly as it gives the portfolio added diversification. The other assets, fixed interest, equity and short term assets then compete for the funds that remain from these previous two allocations.

We specify two models. One is "static", which suggests that life offices are in equilibrium; the other is a pseudo-dynamic one incorporating the stock adjustment mechanism referred to in section 2 by virtue of a one period lag. We include in the equations supply constraints in the form of published data on new issues for the marketable securities (government, debentures and ordinary shares). We might reasonably expect supply conditions to be an important factor affecting net acquisitions, particularly as purchasing by new issues can not only save on costs but can, unless there is a tender system, allow the purchase of relatively large blocks, without undue effect on price. We tackle the question of yields by using a mixture of yield gaps and own yields. Over the whole of our data period there has been a permanent "reverse" yield gap, that is yields on fixed interest securities have been in excess of those on ordinary shares. We use two measures in the model ; $R^{D}-R^{01}$ which is the yield gap between company debentures and ordinary shares (dividend yield) and $R^{L}-R^{01}$ which is the yield gap between government securities of over 15 years to maturity and ordinary shares. The presence of the reverse yield gap points to the fact that investors have come to accept that ordinary shares are a better hedge against inflation than fixed interest securities. Another yield gap we employ is the one between long government securities and long corporate bonds $\left(R^{D}-R^{L}\right)$ referred to earlier, with the premium being a reward for the default and marketability differences. In addition to these yield gaps we also use the own rate on short-term assets $\left(R^{S T A}\right)$ and property $(H P I)$. All the rate are lagged one period. The reasoning for this is that they are all end quarter rates, so the appropriate yield on which decisions would be taken in $t$ is that ruling at the end of $t-1$. We go one stage further of course, as we have already indicated, and argue that these are expected rates. The other regressors that require some explanation are the dummy $(D(2))$, the Building Society liquidity ratio (BSLiq) and the income variable (TNAA1). Taking them in order, the shift dummy is there to pick up changes in structure in the corporate bond market in 1969 caused by the decision of the government to free capital gains on government securities held for one year or more, and the decision to end its open buying policy of government securities. The Building Society ratio is present in the loans and mortgages equation to pick up the house purchase element, the hypothesis being that in periods when the house purchase market is booming (low liquid assets ratio), there is a spill-over effect into life assurance loans for house purchase and life companies are passive suppliers. The income variable is total net acquisitions adjusted for the prior allocations made to corporate bonds and mortgages. 


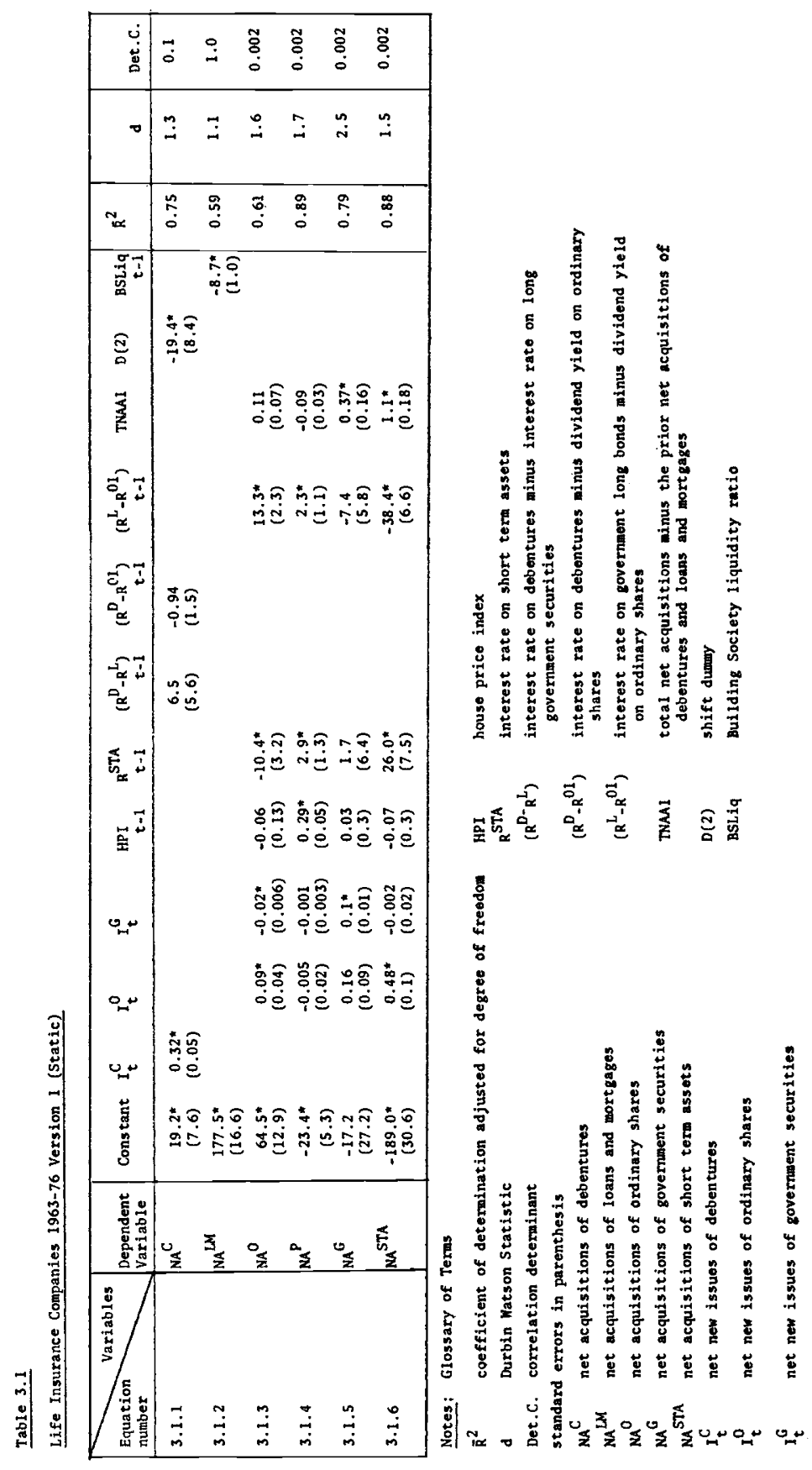


If we take the models separately we can see in the case of the static model (table 3.1) that overall the results are quite good as far as the fit is concerned $\left(\bar{R}^{2}\right)$, though the Durbin Watson statistic could be improved in some equations. There does not appear to be any serious multicollinearity.

In the debentures equation (equation 3.1.1) the issues coefficient is correctly signed (positive) and statistically significant as is the shift dummy, but the two yield gaps are insignificant at the $5 \%$ level. The signs achieved on the latter however, can be justified on a priori reasoning. In the case of yield gap with government securities, a widening of the gap ( + sign) would favour the acquisition of debentures. The negative sign on the reverse yield gap $\left(R^{D}-R^{01}\right)$ would signal that as the gap narrows, debentures can become a more attractive proposition. Overall the fit is encouraging but the Durbin Watson statistic does indicate the presence of autocorrelation.

For the loans and mortages equation (equation 3.1.2) the single regressor, BSLiq performs quite well with the negative sign indicating a spillover into borrowing from life offices in booming house market conditions. The modest fit needs to be improved on and one possibility would be to further disaggregate loans and mortgages so as to bring out the house purchase element (over $50 \%$ of the total) as a separate asset grouping.

In the ordinary shares equation (equation 3.1.3), the own issues coefficient is correctly signed and significant and so is the coefficient on the issues of government securities $\left(I^{G}\right)$ if we regard the two securities as broadly substitutes. The reverse yield gap $\left(R^{L}-R^{01}\right)$ is significant with the positive sign supporting the reasoning that as the gap widens, the net acquisitions of ordinary shares will increase. The yield on shortterm assets $(R S T A)$ is significant with a negative sign indicative of the hypothesis that net acquisitions increase with a falling short rate ; which is what one could reasonably expect. The adjusted income coefficient (TNAA1), whilst correctly signed, is only significant at the $10 \%$ level. The coefficient on the yield on property $(H P I)$ is not significant but is also correctly signed if property and ordinary shares, both equity assets are regarded as substitutes. Overall with a fit of $61 \%$ this equation needs to be improved.

The property equation (equation 3.1.4) appears to be well specified and the own yield $(H P I)$ is correctly signed and significant. The coefficients on the issues of the other marketable assets are negatively signed, what one might expect if they are to be regarded as substitutes, but they are not significant. The reverse yield gap $\left(R^{L}-R^{01}\right)$ coefficient with a positive sign would seem to confirm this in the case of ordinary shares as this result is similar to that obtained in equation 3.1.3. However, whilst the short-term asset yield is significant, the positive sign would indicate a build up of property investment at a time of rising short-run interest rates. In fact a rising interest rate structure usually signals the end to a property boom so that to justify this sign requires us to argue that life offices continue buying in a falling market. The final regressor is the adjusted income variable and this is not significant and it has a negative sign. The overall fit of $89 \%$ is however encouraging.

In the government securities equation (equation 3.1.5) a good overall fit is still obtained $(79 \%)$ but only two coefficients are significant: own issues $\left(I^{G}\right)$ and the adjusted income variable (TNAA1). The negative sign on the reverse yield gap $\left(R^{L}-R^{01}\right)$ 
is arguing, as in the case of debentures, for an increased net acquisition as the gap narrows. The signs on the other insignificant variables, $H P I, R^{S T A}, I^{O}$ all appear perverse. This equation is thus a little disappointing given the importance of government securities in the portfolios of life offices.

The final equation, for short term assets (equation 3.1.6) has a good fit. The own yield, adjusted income variables are both significant and correctly signed. The negative sign on the reverse yield gap $\left(R^{L}-R^{01}\right)$ can be rationalized if the narrowing is due to falling prices in the equity market which can lead to a build up of short-term assets. But for this conjecture to hold we would need to have a negative sign in the coefficient of issues of ordinary shares $\left(I^{O}\right)$; instead this variable has a positive sign as well as being significant. The negative signs on the other two variables, $I^{G}$ and $H P I$ can all be justified on the basis of short term assets being a buffer asset and thus directly substitutible with government securities and property. However, neither coefficient is significant at the $5 \%$ level.

If we turn to the dynamic version of the model (table 3.2 ) where we have included a lagged dependent variable, this improves the loans and mortages equation but the others are virtually unchanged. We can no longer rely on the Durbin Watson statistic with the presence of a lagged dependent variable since this statistic is biased towards a value of 2.0. The main difference in the results is that in the Government securities equation (equation 3.2.5) the issues of ordinary shares $\left(I^{\circ}\right)$ now become significant at the $5 \%$ level. We are therefore conscious that these results are still far from perfect and that further work is necessary, and it is to this aspect that we turn our attention in Section 4.

\section{Perspective and conclusion}

The focus of this paper has been to take the life insurance industry as a sector rather than to adopt a company or cross-section approach.

The models we have adopted focus on strategic choices among asset classes. We have not covered choice and switching within asset classes, though this again is an area which would repay a detailed coverage. This is probably only possible on a "micro" basis. Micro studies are an area where further work needs to be done and if the linkages between micro and macro models could be developed, then we would have a detailed and comprehensive picture of the investment process in the life insurance industry. We recognise that further refinement and improvements of our models would be possible and indeed the whole concept of a sequential investment process could still be questioned. If we accept the format of the approach taken, refinements could be made in the present model by estimating an equation for life insurance policy reserves and then re-estimating the model using two stage least squares and instrumental variables. Having gone so far as to estimate a simultaneous model of this type, it would be a logical step to develop linkages with the real sector of the economy, though we recognise the difficulties of this particular approach. 


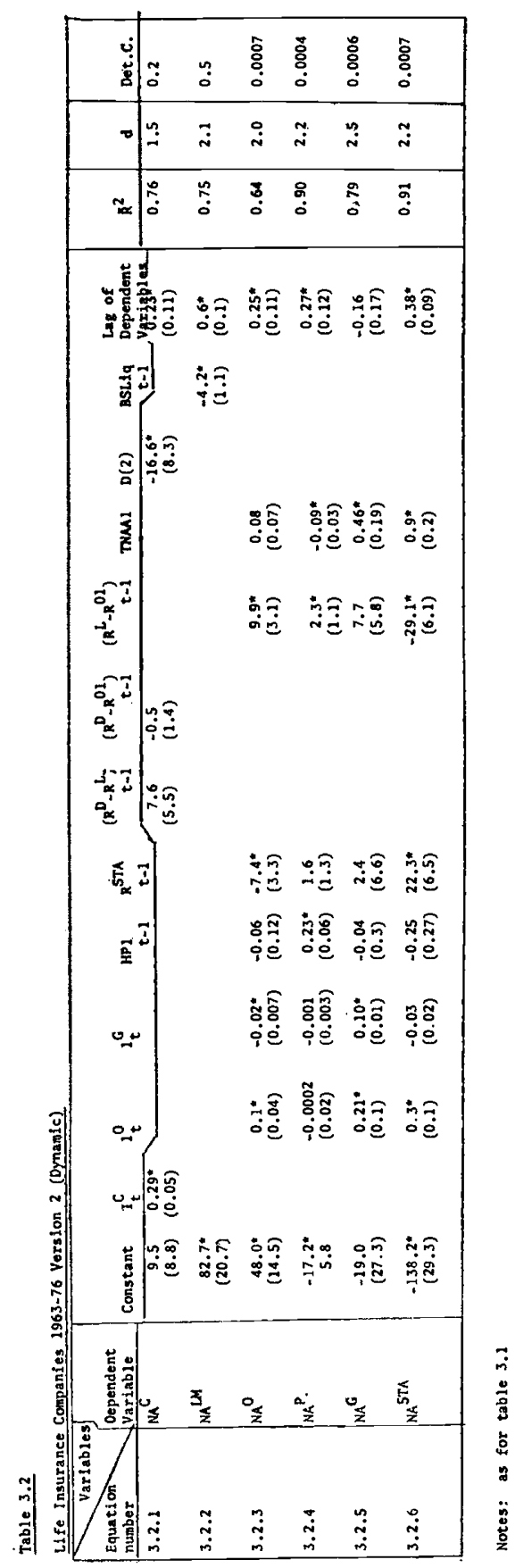




\section{REFERENCES}

1. CARTER, R. L. : Economics and Insurance, An Introduction to the Economic Aspects of Insurance, P. H. Press, Stockport, 1972.

2. CARTER, R.L., and JOHNSON, J.E.V.: "The investment policy of British life offices", Discussion Paper No. 42 in Industrial Economics, University of Nottingham, 1976.

3. CLARKE, H. G. : "A broad analysis of the problem of the investment of life funds", Journal of the Institute of Actuaries 80, 1954, 335-364.

4. CLAYTON, G.: British Insurance, Elek, London, 1971.

5. CLAYTON G., and OSBORN, W. T.: Insurance Company Investment, Principles and Policy, Allen and Unwin, London, 1965.

6. COTTRELL, H. C. : Discussion on the paper by H. G. Clarke [3], Journal of the Institute of Actuaries 80, 1954, 376-377.

7. DICKINSON, G. M. : " Determinants of insurance company asset choice", The Withdean Papers No. 2, 1971.

8. DODDS, J.C.: "The demand for financial assets by the British life funds - A comment ", Oxford Bulletin of Economics and Statistics 57, May 1975, 159-164.

9. DODDS, J.C.: The Investment Behaviour of British Life Insurance Offices, 1963-76. Croom Helm, London, 1979.

10. FRANKLIN, P. J., and WOODHEAD, C. : The U.K. Life Assurance Industry - A Study in Applied Economics. Forthcoming, Croom Helm, London, 1979.

11. MUNRO, A. : "Investment policy of U.K. life offices - A flow of funds model", Discussion Paper No. 29, University of Stirling, 1974.

12. RYAN, T.M.: "The demand for financial assets by the British life funds", Oxford Bulletin of Economics and Statistics, 35, February 1973. 